\title{
UJI AKTIVITAS ANTIBAKTERI BEBERAPA SPONS DARI PERAIRAN SALIBABU KEPULAUAN TALAUD
}

\section{(Antibacterial Activity of Several Sponges From the Salibabu Waters of the Talaud Isalands)}

\author{
Remus B. Maradou ${ }^{1}$, Fitje Losung ${ }^{1}$, Remy E. P. Mangindaan ${ }^{1}$, Rosita A. J. \\ Lintang ${ }^{1}$, Wilmy E. Pelle ${ }^{1}$, Hariyani Sambali ${ }^{2}$
}

1. Program Studi IImu Kelautan, FPIK Unsrat

*e-mail: remusbenyaminmaradou@gmail.com

\begin{abstract}
Sponge is one component of coral reefs that has the potential as a bioactive compound however has not been widely used. This study was directed to obtain some spongy crude extracts from the Salibabu waters of the Talaud Islands, determine the antibacterial activity of some crude extruded sponges and compare the antibacterial activity of the sponge fraction against $E$. coli and $S$. aureus test bacteria. The results of identification of sponges were found in three species consisting of: Siphonodictyon sp., Ircinia sp., Dysidea sp. The antibacterial activity of crude extract, water, methanol and hexane fractions using agar diffusion method with $E$. coli and $S$. aureus test bacteria. The crude extract of Siphonodictyon sp and the water fraction of this extract showed the highest antibacterial activity.
\end{abstract}

Key words: Spons, Antibacterial, E. coli. S. aureus

\section{ABSTRAK}

Spons merupakan salah satu komponen terumbu karang yang berpotensi sebagai senyawa bioaktif namun belum banyak dimanfaatkan. Penelitian ini diarahkan untuk menperoleh beberapa ekstrak kasar spons dari perairan Salibabu Kepulauan Talaud, menentukan aktivitas antibakteri dari beberapa ekstrsk kasar spons serta membandingkan aktivitas antibakteri fraksi spons terhadap bakteri uji $E$. coli dan $S$. aureus. Hasil identifikasi spons ditemukan sebanyak tiga spesies yang terdiri dari: Siphonodictyon sp., Ircinia sp., Dysidea sp. Pengujian aktivitas antibakteri ekstrak kasar, fraksi air, metanol dan heksan menggunakan metode difusi agar dengan bakteri uji $E$. coli dan $S$. aureus. Ekstrak kasar siphonodictyon sp dan fraksi air dari ekstrak ini menunjukan aktivitas antibakteri tertinggi.

Kata kunci : Spons, Antibakteri, E. coli, S. aureus. 


\section{PENDAHULUAN}

Indonesia merupakan negara kepulauan terbesar di dunia yang memiliki wilayah laut sangat luas dengan panjang pantai $99.093 \mathrm{~km}$ (Badan Informasi Geospasial, 2015). Hal ini berkaitan erat dengan keanekaragaman sumberdaya hayati laut yang tinggi, salah satunya ialah ekosistem terumbu karang. Dalam ekosistem terumbu karang hidup berbagai biota laut, termasuk di dalamnya spons laut. Spons merupakan salah satu komponen biota penyusun terumbu karang yang mempunyai potensi senyawa bioaktif yang belum banyak dimanfaatkan (Muniarsih dan Rachmaniar. 1999). Spons laut memiliki potensi bioaktif yang sangat besar selama kurang lebih 50 tahun terakhir banyak senyawa bioaktif yang telah ditemukan dari spons (Bara, 2007). Berbagai substansi bioaktif telah berhasil ditemukan seperti antibakteri dari spons yang dapat menghambat pertumbuhan bahkan membunuh bakteri (Mangindaan et al., 1997).

Resistensi antibiotik merupakan permasalahan penting di bidang kesehatan. Berbagai jenis kuman patogen berkembang menjadi resisten terhadap satu atau beberapa jenis antibiotik. Resistensi terjadi akibat penggunaan antibiotik yang tidak rasional sehingga antibiotik yang dulunya berpotensi dalam membunuh bakteri kehilangan kemampuannya (Wang et al., 2006). Peningkatan resistensi bakteri terhadap antibiotik merupakan ancaman serius terhadap bidang kesehatan, karena itu diperlukan penemuan dan pengembangan jenis antibiotik baru yang dapat melawan mekanisme resistensi yang sudah ada. Kebutuhan antibiotik baru masih sangat diperlukan, terutama yang efektif melawan bakteri resisten (Suwandi, 1993). Untuk menanggulangi permasalahan tersebut maka perlu dilakukan eksplorasi dan pengembangan terhadap berbagai sumber senyawa antibiotik misalnya bahan bioaktif dari spons laut.

\section{METODE PENELITIAN}

\section{Pengambilan dan Penanganan Sampel Spons}

Sampel spons diambil dari perairan Salibabu Kepulauan Talaud (Gambar 1). Proses pengambilan sampel dilakukan dengan cara dipotong langsung pada substratnya pada kedalaman air kurang dari 0,5 meter. Selanjutnya sampel spons ditimbang untuk mengetahui berat sampel.

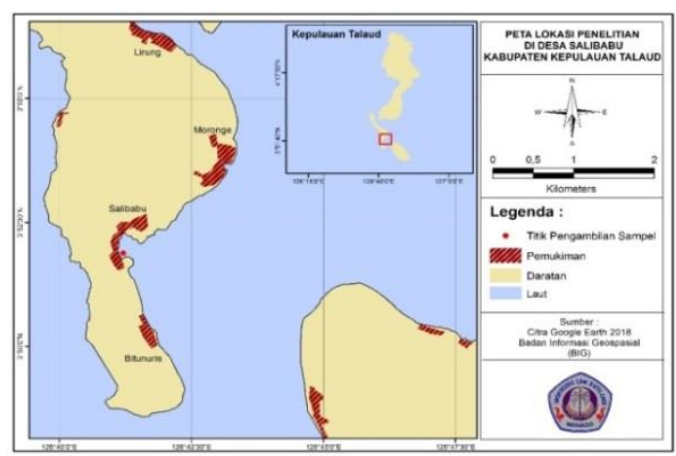

Gambar 1. Lokasi Pengambilan Sampel

\section{Identifikasi Spons}

Identifikasi spons dilakukan dengan cara mengamati bentuk, warna dan tekstur tubuh yang dimiliki spons. Hasil pengamatan morfologi spons kemudian dilihat pada situs www.spongeguide.org.

\section{Ektraksi Spons}

Proses ekstraksi dilakukan dengan cara maserasi. Sampel spons ditimbang untuk mengetahui berat sampel. Kemudian sampel dipotongpotong berbentuk dadu/kubus lalu dimasukkan kedalam botol dan direndam dengan etanol $95 \%$ selama $1 \times 24$ jam kemudian disaring menggunakan kertas saring Whatman. Kemudian dievaporasi menggunakan rotary vacum evaporator pada suhu $40^{\circ} \mathrm{C}$ sampai etanol benar-benar menguap hingga tersisa ekstrak 
kasar/crude extract. Ekstrak kasar kemudian ditimbang untuk mengetahui berat ekstrak kasar yang diperoleh.

\section{Partisi Spons}

Ekstrak kasar yang diperoleh dari hasil evaporasi dipartisi dengan pelarut air, etil asetat, metanol dan n-heksan. Prosedur kerja partisi dilakukan dengan menambahkan air dan etil asetat pada ekstrak kemudian dimasukan ke dalam corong pisah (separatory funnel) lalu dikocok dan didiamkan selama 10 menit, sehingga terlihat 2 lapisan yaitu lapisan air dan lapisan etil asetat. Masing-masing lapisan dikeluarkan dan ditampung dalam wadah. Lapisan etil asetat dievaporasi menggunakan rotary vacum evaporator pada suhu $40^{\circ} \mathrm{C}$ ekstrak etil asetat kemudian dipartisi kembali dengan menambahkan pelarut heksan dan metanol (perbandingan 1:1) selanjutnya dimasukkan ke dalam corong pisah (separatory funnel) dikocok dan didiamkan selama 10 menit sehingga nampak adanya 2 lapisan yaitu lapisan heksan dan lapisan metanol. Fraksi-fraksi hasil partisi yaitu fraksi air, metanol dan nheksan dievaporasi menggunakan rotary vacum evaporator sampai kering kemudian ketiga fraksi diperoleh ditimbang.

\section{Sterilisasi Alat dan Bahan}

Alat-alat yang digunakan pada penelitian ini seperti gelas erlenmeyer, cawan petri, tabung reaksi dan beberapa peralatan gelas lainnya dicuci bersih, dikeringkan lalu dibungkus dengan kertas dan disterilkan dalam oven pada suhu $160^{\circ} \mathrm{C}$ selama \pm 120 menit (sterilisasi kering). Sedangkan untuk media di autoklaf selama 15 menit pada suhu $121{ }^{\circ} \mathrm{C}$ (sterilisasi basah).

\section{Pembuatan Media}

\section{Media Nutrient Broth (NB)}

Media Nutrient Broth dibuat sebanyak 2 erlenmeyer yang digunakan untuk kultur bakteri $E$. coli dan $S$. aureus. Pembuatan media Nutrient Broth dilakukan dengan cara melarutkkan 0,65 gram Nutrient Broth ke dalam $50 \mathrm{ml}$ air kemudian dihomogenkan. setelah itu erlenmeyer ditutup menggunakan aluminium foil dan diautoklaf pada suhu $121{ }^{\circ} \mathrm{C}$ selama kurang lebih 15 menit.

\section{Kultur Bakteri}

Media Nutrient Broth yang sudah disiapkan sebelumnya, ditambahkan masing-masing bakteri yaitu bakteri $E$. coli dan S. aureus. Bakteri diambil menggunakan jarum ose kemudian dimasukkan ke dalam masing-masing erlenmeyer, setelah itu dibungkus dengan kertas aluminium foil dan dibiarkan selama 1x24 jam.

\section{Media Nutrient Agar}

Prosedur pembuatan media Nutrient Agar (NA) sebagai berikut : 1 gram Nutrient Broth (NB), 1,5 gram Agar dan $100 \mathrm{ml}$ air. Media Nutrient Agar dibuat dalam dua erlenmeyer untuk bakteri $E$. coli dan $S$. aureus. Media dalam erlenmeyer dihomogenkan, setelah itu ditutup menggunakan aluminium foil untuk diautoklaf pada suhu $121{ }^{\circ} \mathrm{C}$ selama kurang lebih 15 menit. Selanjutnya media dibiarkan sampai hangat lalu masukkan masing-masing bakteri $E$. coli dan $S$. aureus. yang sebelumnya telah dikultur pada media Nutrient Broth menggunakan mikropipet yang berukuran $1000 \mu \mathrm{l}$ diambil sebanyak $1000 \mu \mathrm{l}$ atau $1 \mathrm{ml}$, kemudian ditutup dan dibungkus kembali dengan kertas aluminium foil dan diaduk dengan cara menggoyangkan erlenmeyer satu arah, setelah itu dituangkan ke dalam setiap cawan petri.

\section{Pembuatan Kontrol Positif dan Negatif}

Pengujian antibakteri ekstrak kasar dan fraksi spons menggunakan kontrol positif dan kontrol negatif sebagai pembanding, dimana kontrol positif menggunakan obat kloramfenikol 
yang sudah (paten) digunakan sebagai obat antibakteri dan kontrol negatif menggunakan etanol yang digunakan sebagai pelarut untuk ekstraksi. Kontrol positif dibuat dengan melarutkan 250 mg obat kloramfenikol ke dalam $250 \mathrm{ml}$ air. Kontrol negatif menggunakan pelarut etanol dengan konsentrasi $40 \%$.

\section{Pengujian Aktivitas Antibakteri}

Metode yang digunakan pada penelitian pengujian aktivitas antibakteri dari ekstrak kasar dan fraksi spons adalah metode difusi agar (disc diffusion Kirby and Bauer). Kertas cakram (paper disc) yang digunakan pada pengujian antibakteri ini berukuran $6 \mathrm{~mm}$ dengan daya serap 50 $\mu \mathrm{l}$ tiap kertas cakram.

Proses pengujian menggunakan konsentrasi $100 \mathrm{mg} / \mathrm{ml}$. pada kertas cakram ditotolkan sebanyak $50 \mu \mathrm{l}$ ekstrak kasar, fraksi air, fraksi metanol, fraksi heksan, kontrol positf (kloramfenikol) dan kontrol negatif (etanol 40\%). Setelah selesai, seluruh kertas cakram diletakkan diatas media yang berisikan masing-masing bakteri uji E. coli dan S. aureus.

\section{Pengamatan dan Pengukuran}

Pengamatan aktivitas antibakteri dilakukan setelah 1×24 jam masa inkubasi berakhir sehingga tepian atau pinggir zona hambat dapat ditetapkan sebagai diameter zona hambat. Diameter zona hambat diukur dalam satuan milimeter $(\mathrm{mm})$ menggunakan mistar berskala dengan cara mengukur diameter total zona hambat dari kertas cakram (Mokodompit et al., 2015).

\section{HASIL DAN PEMBAHASAN}

\section{Pengambilan dan Penanganan Sampel Dilapangan}

Pengambilan sampel dilakukan di perairan Salibabu Kepulauan Talaud. Di dapatkan tiga jenis spons dengan berat masing-masing sampel seperti yang ditunjukan oleh Tabel 1.
Tabel 1. Berat Sampel

\begin{tabular}{|c|c|c|}
\hline No & Kode Sampel & Berat Basah (g) \\
\hline 1 & Sal 1 & 535 \\
\hline 2 & Sal 2 & 479 \\
\hline 3 & Sal 3 & 456 \\
\hline
\end{tabular}

\section{Identifikasi Sampel}

Tiga spesis spons yang diambil dari perairan Salibabu Kepulauan Talaud telah diidentifikasi berdasarkan warna, bentuk dan tekstur tubuh yang dimiliki spons menurut panduan www.spongeguide.org. Hasil identifikasi tiga jenis spons, diketahui ciri-ciri spons seperti yang tertera pada Gambar 2, 3, 4.
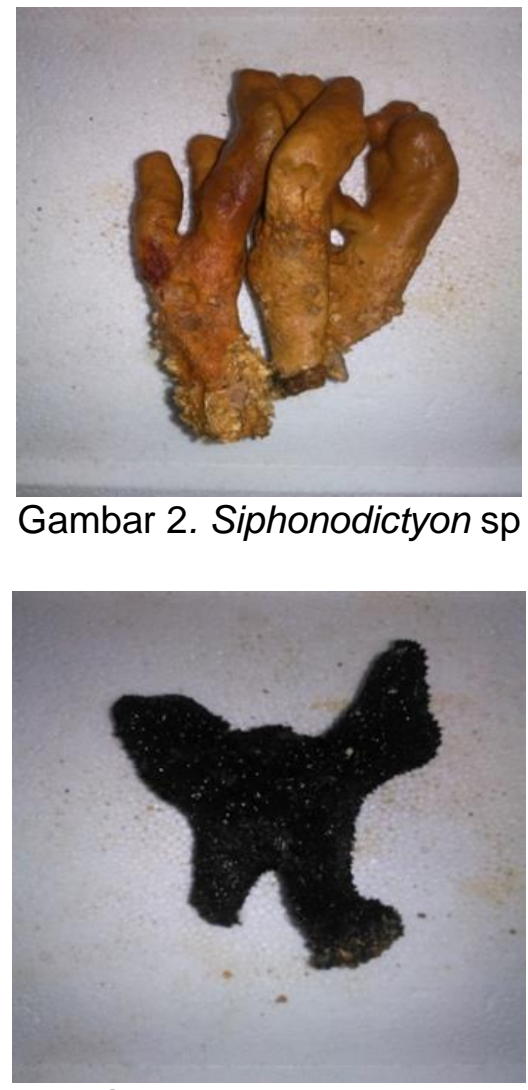

Gambar 3. Ircinia sp 


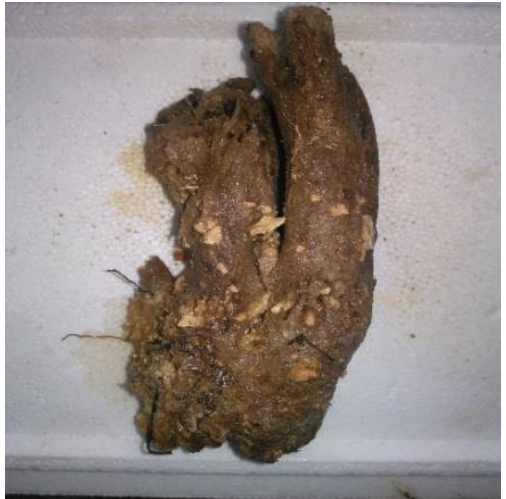

Gambar 4. Dysidea sp

\section{Ekstraksi Spons}

Dari hasil ekstraksi dengan metode maserasi selama $1 \times 24$ jam didapatkan filtrat yang di dalamnya diduga mempunyai senyawa aktif. Filtrat disaring dan dievaporasi didapatkan ekstrak kasar spons dengan berat masing-masing ekstrak kasar spons seperti tertera pada Tabel 2 .

Tabel 2. Berat Ekstrak Kasar Spons.

\begin{tabular}{|l|c|c|}
\hline \multicolumn{1}{|c|}{ Sampel } & $\begin{array}{l}\text { Berat } \\
\text { Basah } \\
\text { (g) }\end{array}$ & $\begin{array}{l}\text { Berat } \\
\text { Ekstrak } \\
\text { kasar (g) }\end{array}$ \\
\hline $\begin{array}{l}\text { Siphonodictyon } \\
\text { sp }\end{array}$ & 535 & 34,6 \\
\hline Ircinia sp & 479 & 16,8 \\
\hline Dysidea sp & 456 & 17,4 \\
\hline
\end{tabular}

\section{Partisi Spons}

Ekstrak kasar yang memiliki aktivitas antibakteri terbesar dilanjutkan dengan partisi. Ekstrak kasar yang dipartisi yaitu ekstrak Siphonodictyon sp. Partisi menggunakan 4 jenis pelarut yaitu pelarut air, etil asetat, metanol, dan n-heksan. Partisi ekstrak menggunakan pelarut air dan etil asetat menampilkan dua lapisan terpisah, lapisan air di bagian bawah dan lapisan etil asetat di bagian atas. Hal ini dikarenakan kepolaran air lebih tinggi dibandingkan dengan kepolaran etil asetat. Lapisan etil asetat di evaporasi dan dipartisi kembali menggunakan pelarut metanol dan heksan. Dari proses partisi kedua lapisan terpisah dengan lapisan metanol pada bagian bawah dan heksan pada bagian atas.
Kemudian masing-masing lapisan dievaporasi dan ditimbang untuk mendapatkan berat ekstrak dari masing-masing fraksi Tabel 3.

Tabel 3. Berat Fraksi Spons

\begin{tabular}{|c|l|c|}
\hline No. & Fraksi Sampel & Berat Fraksi (g) \\
\hline 1. & Fraksi Air & 1,078 \\
\hline 2. & Fraksi Metanol & 1,227 \\
\hline 3. & Fraksi N-heksan & 1,176 \\
\hline
\end{tabular}

\section{Pengujian Aktivitas Antibakteri Pengujian Aktivitas Antibakteri Ekstrak kasar Spons}

Dari hasil pengujian tiga ekstrak kasar spons yaitu Siphonodictyon sp, Ircinia sp, dan Dysidea sp, kontrol positif (kloramfenikol) dan kontrol negatif (etanol $40 \%$ ) yang diujikan pada bakteri E.coli, dan S. aureus. Gambar 5.
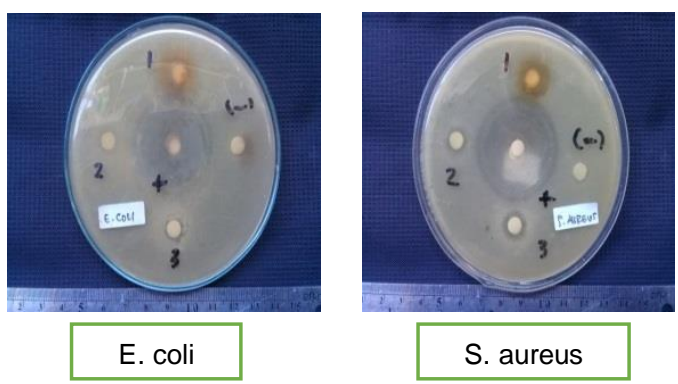

Gambar 5. Aktivitas Antibakteri Ekstrak Kasar.

Hasil pengukuran zona hambat yang ditunjukan oleh ketiga ekstrak kasar, kontrol positif (kloramfenikol) dan kontrol negatif (etanol 40\%), diketahui bahwa ketiga ekstrak kasar spons dapat memberikan zona hambat terhadap bakteri E.coli dan S. aureus. 
Tabel 4. Diameter Zona Hambat Ekstrak Kasar Spons

\begin{tabular}{|l|c|c|}
\hline \multirow{2}{*}{ Sampel } & \multicolumn{2}{|c|}{$\begin{array}{c}\text { Diameter Zona } \\
\text { Hambat (mm) }\end{array}$} \\
\cline { 2 - 3 } & E.coli & S. aureus \\
\hline $\begin{array}{l}\text { Siphonodictyon } \\
\text { sp }\end{array}$ & 11.00 & 15.00 \\
\hline Ircinia sp & 8.00 & 10.00 \\
\hline Dysidea sp & 7.00 & 11.00 \\
\hline Kontrol positif & 20.00 & 24.00 \\
\hline Kontrol negatif & - & - \\
\hline & &
\end{tabular}

Pengujian Aktivitas Fraksi Partisi Spons

Hasil pengujian aktivitas antibakteri dari ekstrak uji terhadap bakteri E.coli (Gambar 6) pada ketiga ulangan hanya fraksi air dan kontrol positif yang menunjukan zona hambat (inhibitory zone). Fraksi air menunjukan diameter zona hambat pada ulangan I $(10,00 \mathrm{~mm})$, ulangan II $(11,00 \mathrm{~mm})$, dan ulangan III $(11,00 \mathrm{~mm})$. Selanjutnya kontrol positif (kloramfenikol) menunjukan diameter zona hambat pada ulangan I $(20,00$ $\mathrm{mm})$, Ulangan II $(21,00 \mathrm{~mm})$, dan Ulangan III (19,00 mm).
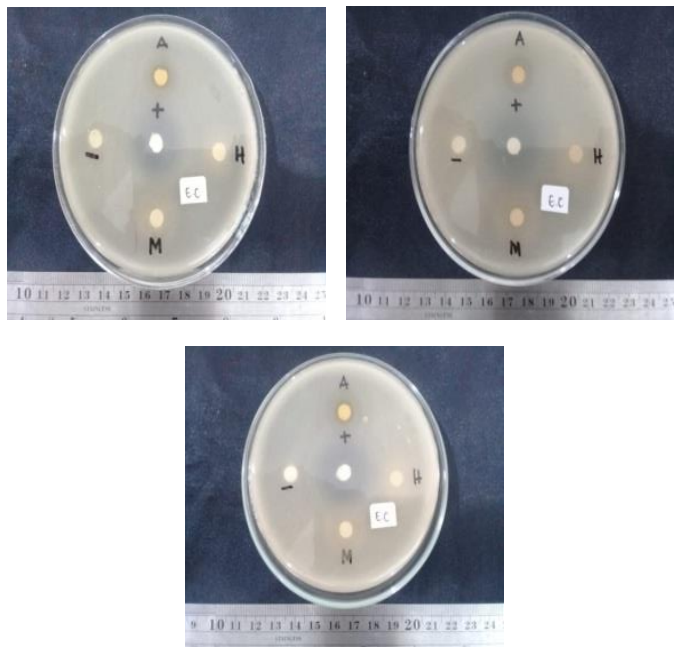

Gambar 6. Aktivitas antibakteri fraksi partisi pada media bakteri E.coli.
Aktivitas antibakteri pada bakteri S. aureus (Gambar 7) pada ketiga ulangan hanya fraksi air dan kontrol positif yang menunjukan zona hambat (inhibitory zone). Fraksi air menunjukan diameter zona hambat pada ulangan I $(15,00 \mathrm{~mm})$, pada ulangan II $(14,00$ $\mathrm{mm})$, dan Ulangan III (14,00 mm). Selanjutnya kontrol positif (kloramfenikol) menunjukan diameter zona hambat pada ulangan I $(25,00$ $\mathrm{mm})$, ulangan II $(25,00 \mathrm{~mm})$, dan ulangan III $(25,00 \mathrm{~mm})$
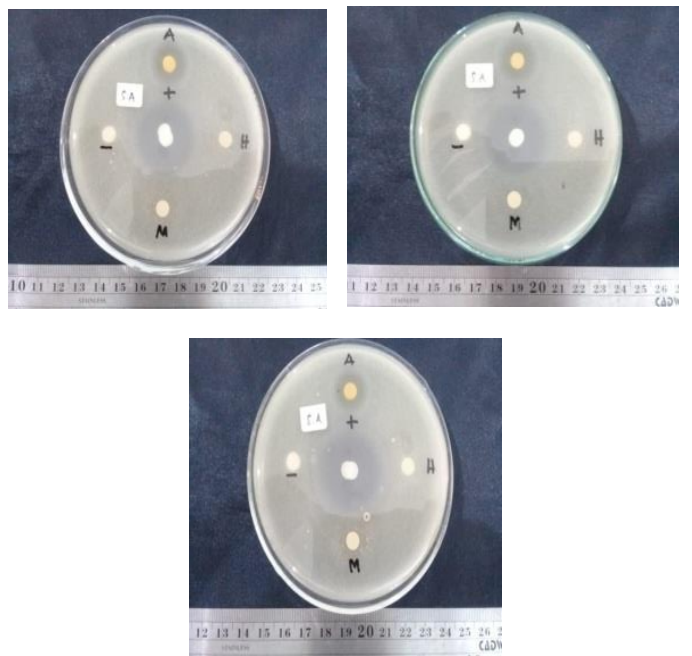

Gambar 7. Aktivitas antibakteri fraksi partisi pada media bakteri S. aureus.

Tabel 5. Rerata zona Hambat Fraksi Siphonodictyon sp terhadap pertumbuhan bakteri E.coli dan S. aureus.

\begin{tabular}{|l|c|c|}
\hline \multirow{2}{*}{$\begin{array}{c}\text { Siphonodictyo } \\
\boldsymbol{n} \text { sp }\end{array}$} & \multicolumn{2}{|c|}{$\begin{array}{c}\text { Rerata Zona Hambat } \\
\text { Media E.coli dan S. } \\
\text { aureus (mm) }\end{array}$} \\
\cline { 2 - 3 } & E.coli & S. aureus \\
\hline Fraksi Air & 10.66 & 14.33 \\
\hline $\begin{array}{l}\text { Fraksi N- } \\
\text { heksan }\end{array}$ & - & \\
\hline Fraksi Metanol & - & - \\
\hline Kontrol (-) & - & - \\
\hline Kontrol (+) & 20.00 & 25.00 \\
\hline
\end{tabular}


Menurut Davis dan Stout (1971) penggolongan kriteria kekuatan suatu bahan antibakteri adalah sebagai berikut, yakni diameter zona hambat 5 $\mathrm{mm}$ atau kurang dikategorikan lemah, dan zona hambat 5-10 dikategorikan sedang, sedangkan diameter zona hambat $10-20 \mathrm{~mm}$ dikategorikan kuat dan bahkan lebih dari 20 dinyatakan senyawa yang memiliki aktivitas antibakteri yang sangat kuat. Dari data yang ditampilkan oleh Tabel 8 dapat dijelaskan bahwa hanya fraksi air memberikan daya hambat terhadap pertumbuhan bakteri E.coli dan $S$. aureus. Pada bakteri E.coli zona hambat yang dihasilkan $10.00 \mathrm{~mm}$ (tergolong sedang) dan pada bakteri $S$. aureus zona hambat $14.00 \mathrm{~mm}$ (tergolong kuat).

Dari hasil yang ditunjukkan diatas bakteri Gram positif cenderung lebih sensitif terhadap komponen antibakteri daripada Gram negatif dikarenakan struktur dinding sel bakteri Gram positif lebih sederhana sehingga memudahkan senyawa antibakteri masuk ke dalam sel dan menemukan sasaran untuk bekerja, sedangkan struktur dinding sel bakteri Gram negatif lebih kompleks (Kusmiyati dan Agustini, 2007).

Kontrol positif kloramfenikol yang dipakai memiliki zona hambat yang lebih besar dibandinkan dengan ekstrak uji. Faktor yang mempengaruhi karena Minimum Inhibitory Concentration (MIC) kloramfenikol yang digunakan telah murni sebagai antibiotik serta telah diketahui bahwa kloramfenikol merupakan antibiotik berspektrum luas, sedangkan untuk kemampuan senyawa dari sampel spons belum diketahui (Patel et al ., 2014).

Kontrol negatif berfungsi untuk menguji apakah pelarut etanol bisa menberikan penghambatan terhadap bakteri atau tidak. Pada pengujian terlihat bahwa kontrol negatif tidak memperlihatkan aktivitas antibakteri, hal ini berarti daya hambat yang terbentuk tidak dipengaruhi oleh pelarut.
Dari hasil pengujian antibakteri didapatkan bahwa senyawa antibakteri dari ekstrak spons, bersipat polar dikarenakan hasil yang ditunjukan yaitu hanya fraksi air dapat menghambat pertumbuhan bakteri E.coli dan $S$. aureus. Dibandingkan dengan hasil penelitian Wewengkang et al., (2014) dari spons Haliclona sp didapatkan senyawa antibakteri bersifat semipolar dikarenakan hasil yang diperoleh hanya fraksi semipolar yakni fraksi kloroform dan metanol yang dapat menghambat pertumbuhan bateri E.coli dan $S$. aureus.

Senyawa antibakteri dapat digolongkan juga sebagai spektrum luas dan spektrum sempit. Spektrum luas artinya senyawa tersebut bekerja aktif terhadap banyak jenis bakteri baik bakteri Gram positif dan bakteri Gram negatif. Sedangkan spektrum sempit artinya suatu senyawa bekerja aktif hanya terhadap satu golongan bakteri saja dan hanya pada bakteri Gram positif ataupun hanya pada bakteri Gram negatif (WHO, 2014). Hasil penelitian ini menunjukan bahwa senyawa antibakteri dari spons yang terdapat pada fraksi air tergolong berspektrum luas dikarenakan kemampuannya menghambat bakteri Gram positif dan bakteri Gram negatif.

\section{KESIMPULAN}

Ekstrak kasar dari tiga jenis spons yaitu : Siphonodictyon sp, Ircinia $\mathrm{sp}$, Dysidea sp, masing-masing sebanyak 34,6 gram, 16,8 gram, 17,4 gram. Daya hambat ekstrak spons baik untuk bakteri $E$. coli maupun $S$. aureus menunjukan bahwa Siphonodictyon yang terkuat diikuti dengan Ircinia dan Dysidea. Aktivitas antibakteri fraksi air dari ekstrak Siphonodictyon sp mencapai setengah dari kontrol positif. Senyawa-senyawa aktif dalam fraksi ini bersifat polar. 


\section{DAFTAR PUSTAKA}

Badan Informasi Geospasial. 2015. Diakses pada 12 Mei 2016 dari https://www.bakosurtanal.go.id.

Bara, R. 2007. Study metabolic rate and metabolism in the spons Haliclona oculata using different ${ }^{13} \mathrm{C}$ labeled substrates. Thesis. Wageningen University. The Netherlands. 47 pp.

Davis dan Stout. 1971. Disc Plate Method Of Microbiological Antibiotic Essay. Journal Of Microbiology. Vol 22 No 4.

Kusmiyati, dan N.W.R. Agustini. 2007. Uji Aktivitas Senyawa Antibakteri dari Mikroalga (Porphyridium cruentum) J. Biod. 8(1): Hal. 4853.

Mangindaan, R. E. P., Nainggolan I. G. S., Losung F. 1997. Anti Mikroba dari Sponge di Teluk Manado. Prosiding Seminar Nasional Hasil dalam Bidang Farmasi. ISBN: 979- 95406-0 (7):544-548.

Mokodompit, A., Boekoesoe, L., Mustapa, M. A. 2015. Uji Aktifitas Antibakteri Ekstrak Etanol Spons Laut (Porifera: Demospongiae) Terhadap Bakteri Staphylococcus aureus dan Escherchia coli. Hal. 3-6.

$\begin{array}{ccr}\begin{array}{c}\text { Muniarsih T., } \\ \text { Isolasi }\end{array} & \begin{array}{c}\text { Rachmaniar } \\ \text { substansi }\end{array} & \text { R. } 1999 . \\ \text { bioaktifif } \\ \text { bikroba dari spons asal Pulau }\end{array}$ dari Kepulauan Seribu. Prosidings seminar bioteknologi kelautan Indonesia. Jakarta $14 \quad-15$ Oktober 1999: Lembaga IImu Pengetahuan Indonesia, Jakarta.

Patel, J.B., F.R. Cockerill., J. Alder., P.A. Bradford., G.M. Eliopoulus., D.J. Hardy., J.A. Hindler., S.G. Jenkins., J.S. Lewis., L.A. Miller., M. Powell., J.M. Swenson., M.M. Traczewski., J.D. Turnigde., M.P. Weinstein., B.L. Zimmer. 2014. Performance Standard for Antimicrobial Susceptibility Testing: Twenty-Fourth Informational Supplement. Vol 34. Clinical and Laboratory Standards Institute. Hal 30-40.

Suwandi, U., 1993, Skrining Mikroorganisme Penghasil Antibiotika, Cermin Dunia Kedokteran, No. 89.

Wang, G., Hindler, J.F., Ward, K.W., and Bruckneer, D.A. 2006. Increased Vancomysin MICS for Staphylococcus aureus Clinical Isolats from a University Hospital during a 5-years Period.

Wewengkang, D.S., Sumilat, D.A., Rotinsulu, H. 2014. Karakterisasi dan Bioaktif Antibakteri Senyawa Spons Haliclona sp. dari Teluk Manado. Jurnal LPPM Bidang Sains dan Teknologi. ISSN: 24076074. 1(1): 71-85.

WHO. 2014. Antimicrobial resistance: global report on survaillance 2014. World Health Organization. 257 Hal. 